\title{
Hedge Fund Return Dependence: Model Misspecification or Liquidity Spirals?
}

\author{
Richard Sias, Harry J. Turtle, and Blerina Zykaj*
}

\begin{abstract}
We test whether model misspecification or liquidity spirals primarily explain the observed excess dependence in filtered (for economic fundamentals) hedge fund index returns and the links between volatility, liquidity shocks, and hedge fund return clustering. Evidence supports the model misspecification hypothesis: i) hedge fund filtered return clustering is symmetric, ii) filtered Short Bias fund returns exhibit negative dependence with filtered returns for other hedge fund types, iii) negative liquidity shocks are associated with clustering in both tails and market volatility subsumes the role of negative liquidity shocks, and iv) these same patterns appear in size-sorted equity portfolios.
\end{abstract}

In the coming months, hundreds of hedge funds may shut their doors, sparking a massive fire sale on all sorts of investments. Just about anybody with a $401(\mathrm{k})$ or pension plan will feel the pain, since the sell-off will only exacerbate the plunge in stocks, bonds, and commodities.

-Businessweek, "The Hedge Fund Contagion" (Oct. 21, 2008)

\section{Introduction}

Hedge fund assets under management grew from \$118 billion in 1997 to over $\$ 2.5$ trillion by 2015 (BarclayHedge.com). It is not clear, however, whether the dramatic growth in hedge fund assets has improved markets. One view holds that hedge funds are smart money rational arbitrageurs with greater freedom to exploit inefficiencies (e.g., ability to short sell and deviate from benchmarks) and, therefore, increase market efficiency (and, ultimately, the efficient allocation of resources). A number of recent studies provide empirical support for this view.

*Sias (corresponding author), sias@eller.arizona.edu, Eller College of Management, University of Arizona; Turtle, harry.turtle@colostate.edu, College of Business, Colorado State University; and Zykaj, bzykaj@clemson.edu, College of Business, Clemson University. We thank George Aragon (WFA discussant), Phelim Boyle, Stephen Brown (the editor), Neal Stoughton, seminar participants at the 2014 Western Finance Association (WFA) meetings, and especially an anonymous referee for their helpful comments. 
For instance, Sias, Turtle, and Zykaj (2016) and Cao, Chen, Goetzmann, and Liang (2016) find that hedge fund demand shocks are positively related to subsequent returns, consistent with hedge fund trades pushing prices toward fundamental values. Similarly, Cao, Liang, Lo, and Petrasek (2017) conclude that, in general, an increase in hedge fund ownership is associated with an increase in intraday price efficiency. However, a contrasting view holds that hedge funds, at least at times, destabilize markets, resulting in less efficient pricing. For instance, one of the major concerns arising from tremendous growth in the hedge fund industry is that poor performance in one segment quickly spreads to other areas via spillover effects, i.e., contagion. ${ }^{1}$ For example, Norris ((2013), p. 18) reports that the Office of Financial Research, a Dodd-Frank created agency in the U.S. Treasury Department, is very concerned about liquidity shock induced hedge fund contagion and quotes a Treasury official, “... 'what you want to know is what happens next.' Perhaps the banks will reduce loans to hedge funds, which might start selling some assets, causing prices to drop and perhaps have negative effects on capital. 'So the first shock leads to a second shock and you also get the contagion."'

In an intriguing model of hedge fund contagion, Brunnermeier and Pedersen (2009) posit that a vicious cycle of deleveraging, increasing margins, and fire sales can cause commonality in poor performance when hedge funds serve as speculators providing market liquidity. Specifically, negative externalities can arise when levered hedge funds suffer an exogenous shock, as an initial loss by a hedge fund will cause the funds to reduce both their positions and market liquidity. Reductions in liquidity cause financiers providing hedge fund leverage to increase margins. This, in turn, further reduces liquidity and creates a margin spiral that causes prices to move further from fundamentals. Moreover, the decline in liquidity drives down prices on initial hedge fund positions, thus forcing additional sales of (knowingly undervalued) shares and further price declines, creating a loss spiral that causes prices to deviate further from fundamentals. The loss spiral and the margin spiral combine to form a self-reinforcing liquidity spiral. ${ }^{2}$

Consistent with the Brunnermeier and Pedersen (2009) model, previous work (e.g., Boyson, Stahel, and Stulz (2010)) demonstrates that hedge fund returns filtered for economic fundamentals exhibit strong positive dependence in left tail (poor) returns (i.e., "contagion") and negative liquidity shocks are associated with an increased likelihood of observing clustering in left tail filtered returns. ${ }^{3}$ These patterns are widely interpreted (e.g., Teo (2011), Hanson and Sunderam (2014), Brown, Gregoriou, and Pascalau (2012), Ben-David, Franzoni, and Moussawi (2012), and Chakrabarty and Zhang (2012)) as evidence that hedge funds destabilize markets via liquidity spirals and have important implications for both

\footnotetext{
${ }^{1}$ Although we focus on the evidence of liquidity-shock induced contagion, hedge funds may destabilize markets for a number of reasons, for example, crowding into the same trades or riding bubbles (e.g., Stein (2009), Brunnermeier and Nagel (2004)).

${ }^{2}$ For ease of exposition, we frame our introductory discussion in terms of a hedge fund with a long position. These same spirals, however, also negatively impact hedge fund short positions.

${ }^{3}$ See also Dudley and Nimalendran (2011). The interpretation of correlation in filtered returns as contagion arises from Bekaert, Harvey, and Ng's (2005) definition of contagion as "correlation over and above what one would expect from economic fundamentals."
} 
understanding markets and regulating hedge funds. As pointed out by Bekaert, Harvey, and $\mathrm{Ng}$ (2005), however, the interpretation of excess dependence as contagion critically depends on the correct specification of the factor model.

In this paper, we reconsider the interpretation that liquidity spirals are primarily responsible for the observed patterns in filtered hedge fund index returns versus the alternative hypothesis that model misspecification primarily explains these patterns. Specifically, we focus on four key predictions from the Brunnermeier and Pedersen (2009) liquidity spiral model versus the predictions that arise from model misspecification. The first test exploits the fact that the Brunnermeier and Pedersen model predicts that filtered return dependence should be asymmetric. That is, the liquidity spiral "factor" is unique because it only impacts commonality in the left tail of the distribution, as a negative funding shock leads to a self-reinforcing liquidity spiral that causes all types of hedge funds to suffer poor (filtered) returns at the same time. There are, however, no upward liquidity spirals. In contrast, model misspecification implies that both the left and right tails of the filtered return distribution will exhibit positive dependence. Consistent with model misspecification, our results demonstrate that filtered hedge fund returns exhibit strong evidence of clustering (i.e., nonindependence) in both tails. Inconsistent with the hypothesis that liquidity shock induced contagion meaningfully contributes to the observed dependence in filtered returns, however, the clustering is symmetric; that is, clustering in right tail filtered returns is as strong as clustering in left tail filtered returns.

Our second test focuses on the model's prediction that liquidity spirals affect both speculator long positions and speculator short positions. As a result, the liquidity spiral model predicts that filtered returns for the hedge fund Short Bias index should exhibit positive dependence with other hedge fund indices in the left tail and be independent of other hedge fund indices in the right tail. In direct contrast, because the Short Bias index will tend to move inversely with economic fundamentals while other indices will tend to move in the same direction as economic fundamentals, the model misspecification explanation predicts that filtered Short Bias index returns will be inversely related to the filtered returns of other hedge fund indices in both tails. Consistent with the model misspecification explanation, filtered Short Bias index returns are strongly inversely related to the filtered returns of other hedge fund indices.

Our third test exploits the liquidity spiral model prediction that negative shocks to liquidity channel variables should increase the likelihood of observing left tail clustering in filtered hedge fund returns and decrease the likelihood of observing right tail clustering in filtered hedge fund returns. In contrast, given fundamental volatility is time varying and liquidity shocks are more likely to occur when fundamental volatility is high, the model misspecification explanation predicts that negative liquidity shocks will be positively associated with the likelihood of observing clustering in both the left and right tails. The intuition is straightforward, as a less than perfectly specified factor model will produce large (correlated) residuals when the (absolute) fundamental shock is large. Again, the evidence supports the model misspecification hypothesis. Specifically, negative liquidity shocks are associated with a stronger likelihood of observing clustering in both the left and right tails. Further, consistent with model misspecification, 
adding a measure of fundamental volatility to the model subsumes the relation between negative liquidity shocks and hedge fund filtered return clustering in either tail.

Our final test exploits the fact that the model predicts hedge fund liquidity spirals should be limited to those assets where hedge funds provide liquidity to other investors. Although hedge funds may provide liquidity for some equities, it is unlikely they serve as the primary liquidity provider for most equities. For example, over our sample period, Cao et al. (2016) report that hedge fund ownership accounted for, on average, 2\% of outstanding shares in 1994 versus $25 \%$ of outstanding shares for other types of institutions. By 2012, however, hedge fund ownership averaged about $9 \%$ of outstanding shares versus $48 \%$ of outstanding shares held by other types of institutions. As a result, it is unlikely hedge fund liquidity shock induced contagion could explain residual dependence or a relation between liquidity shocks and return clustering in both tails for broad equity portfolios. Alternatively, unless we can perfectly specify the return generating model, the model misspecification explanation predicts that we will see the same patterns in passive equity portfolios. The evidence reveals there is nothing unique about the patterns in filtered hedge fund returns. The filtered returns for size ranked equity portfolios also exhibit strong evidence of positive dependence in both tails, negative liquidity shocks are associated with a greater likelihood of observing clustering in both tails, and market volatility subsumes the relation between negative liquidity shocks and return clustering.

Finally, to gauge the potential extent of model misspecification, we run simulations based on data that closely match the empirical distribution of filtered hedge fund returns. Our results indicate that even modest levels of misspecification lead to substantial correlation in (mis-) estimated filtered returns for situations including missing factors, factors measured with errors, time-varying coefficients, or smoothed returns. For instance, suppose an otherwise perfectly specified model is missing a factor that accounts for only $13 \%$ of explained variance (i.e., the model is $87 \%$ "correctly specified") and true filtered returns are independent. In this case, estimated filtered returns that ignore only one (weakly helpful) factor yield average residual correlation levels of $26 \%$.

In sum, we find no support for the hypothesis that liquidity spirals play a meaningful role in explaining filtered hedge fund return clustering or the relation between clustering and negative liquidity shocks. In contrast, our tests uniformly support the hypothesis that model misspecification plays an important role in explaining these patterns. We also consider a number of robustness tests (see Section IV and the Internet Appendix (available at www.jfqa.org)). For example, inconsistent with the hypothesis that liquidity spirals are short lived and monthly returns are too coarse to capture these short-lived spirals, we find the same patterns in daily hedge fund return indices.

Importantly, our results do not imply that negative liquidity shocks never impact hedge fund returns. Rather, our focus is on testing whether the evidence of excess dependence in filtered hedge fund returns or the relation between liquidity shocks and hedge fund filtered return clustering implies that hedge funds cause or exacerbate liquidity spirals via the mechanisms in the Brunnermeier and Pedersen (2009) model. Regardless, our tests suggest that model misspecifications, rather 
than liquidity spirals, primarily underlie both the excess dependence in filtered hedge fund returns and the relation between negative liquidity shocks and filtered hedge fund return clustering. As a result, our analysis has important implications for understanding how markets function, the role of hedge funds in financial markets, and developing appropriate regulations.

\section{Data}

We examine commonality in the filtered returns of monthly hedge fund style indices (HFRI indices) from Hedge Fund Research (HFR). The indices are equal weighted and net of fees, and constituent hedge funds must have at least $\$ 50$ million in assets or more than a 12-month track record. Specifically, our sample includes Equity Market Neutral, Distressed/Restructuring, Merger Arbitrage, Macro, Fixed Income-Convertible Arbitrage, Quantitative Directional, Technology/Healthcare, and Fixed Income-Corporate. Our final sample consists of 228 monthly returns from Jan. 1994 (the beginning of our filtering variables data) through Dec. 2012. It is well recognized (e.g., Fung and Hsieh (2002), (2009)) that hedge fund indices suffer from a number of biases (e.g., backfill bias). Thus, in untabulated robustness tests (see the Internet Appendix for additional detail), we also repeat our primary analysis on hedge fund indices built directly from the underlying hedge funds (to control for these biases) in the HFR database and find nearly identical results.

Following the literature, we control for the impact of economic fundamentals with a time-series regression related to various linear and nonlinear factors. ${ }^{4}$ Specifically, we estimate time-series regressions of monthly hedge fund index returns on 14 factors used by Boyson et al. (2010): the contemporaneous return on the Standard \& Poor's (S\&P) 500, Barclays' Capital Aggregate Bond Total Return Index, a currency index, the 3-month T-bill yield, the monthly change in the 10-year constant maturity T-bond yield, the change in the default premium, five asset-based style (ABS) factors from Fung and Hsieh (2001), a size spread (Russell 2000 return less S\&P 500 return), the negative portion of the S\&P 500 return (as a proxy for a market put option), and the index's own lag value (to help control for return smoothing). The Fung and Hsieh (2001) ABS factors are returns from lookback straddles on bonds, currencies, commodities, interest rates, and stock indices. ${ }^{5}$ The Internet Appendix provides descriptive statistics and additional details for the filtering variables.

Following previous work, the residuals from these time-series regressions serve as the estimate of returns filtered for economic fundamentals. Table 1 presents the summary statistics and correlations for the monthly filtered HFRI indices. Consistent with both liquidity spirals and model misspecifications, the correlations reported in Panel B reveal strong evidence of dependence in filtered hedge fund returns.

${ }^{4}$ See Fung and Hsieh (2001), (2002), (2004), Bollen and Whaley (2009), Dudley and Nimalendran (2011), Titman and Tiu (2011), Patton and Ramadorai (2013), Sialm, Sun, and Zheng (2014), and Bollen (2013).

${ }^{5}$ We thank David Hsieh for making the trend-following risk factors used in Fung and Hsieh (2001), (2004) available on his Web site: http://faculty.fuqua.duke.edu/ dah7/DataLibrary/TF-FAC.xls. 
TABLE 1

Summary Statistics for Filtered Monthly HFRI Returns

Panels A and B in Table 1 present filtered return summary statistics (including $p$-values for tests of departures from normality) and correlations for eight monthly HFRI hedge fund indices, respectively. The sample covers 228 months from Jan. 1994 to Dec. 2012. The filtering variables include the index's own lag return, the S\&P 500 return, the Barclays' Capital Aggregate Bond Index Return, the percent change in a currency index, the 3-month T-bill yield, the change in the 10-year T-bond yield, the change in the default premium, the five Fung and Hsieh (2001) ABS factors, a size spread (Russell 2000 return less S\&P 500 return), and the negative portion of the S\&P 500 return. Correlations with * and ${ }^{* *}$ indicate significance at the $5 \%$ and $1 \%$ levels, respectively.

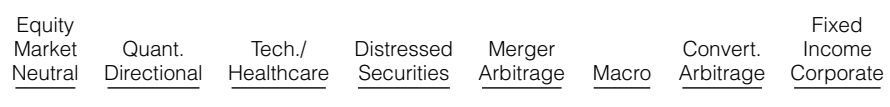

Panel A. Monthly HFRI Filtered Hedge Fund Indices Summary Statistics

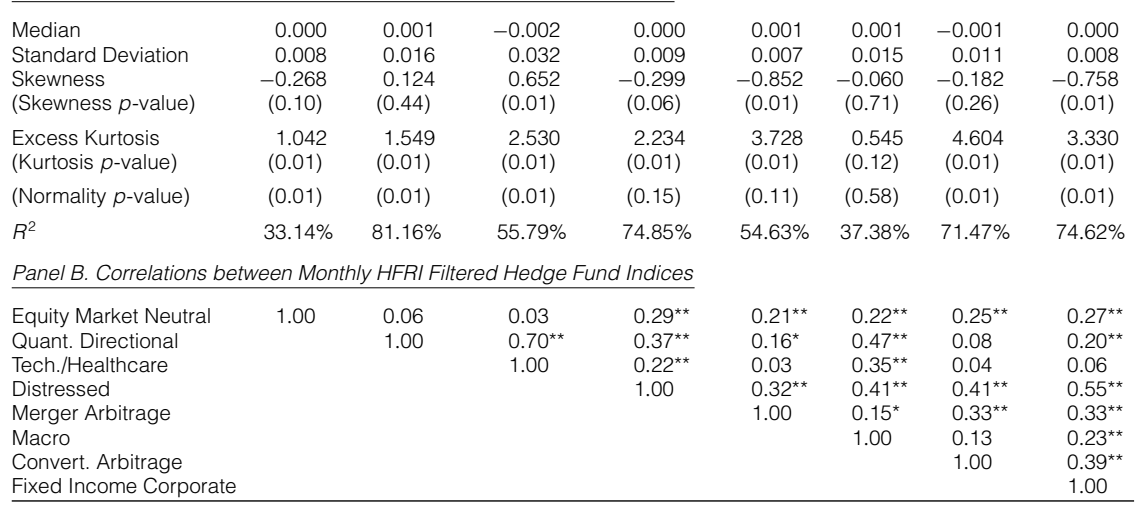

\section{Empirical Tests}

\section{A. Hedge Fund Filtered Return Dependence: Tests for Asymmetry}

The Brunnermeier and Pedersen (2009) model predicts that hedge fund filtered return clustering will be asymmetric because liquidity shock induced contagion spills over across different types of funds in the event of a negative liquidity shock, but there are no contagion effects in the event of a positive shock (see Section V of their paper). In contrast, the model misspecification explanation implies that dependence will be symmetric (i.e., similar dependence in both the left and right tails). We begin to examine hedge fund filtered return dependence with the quantile regression methodology of Cappiello, Kadareja, and Manganelli (2010) and Cappiello, Gérard, Kadareja, and Manganelli (2014). Specifically, to examine left (right) tail clustering, we estimate the probability a hedge fund index has a filtered return below (above) a specified percentile given the average of the other seven indices is below (above) the same percentile for values below (above) the median. Dependence is depicted in a unit square comovement box that plots the estimated probability that a given HFRI index falls below (above) a given quantile conditional on the average of the other seven HFRI indices falling below (above) the same quantile. ${ }^{6}$ In short, values above the no-dependence benchmark

\footnotetext{
${ }^{6}$ The intuition for the comovement box can be described in a simple example. Assuming independence, the joint probability that two variables, say, $\mathrm{Y}$ and $\mathrm{Z}$, both earn a return in the bottom decile in the same month is $0.10 \times 0.10=0.01$. Dividing this joint probability by the likelihood that $\mathrm{Z}$ is in its bottom decile yields 0.10 (i.e., $(0.10 \times 0.10) / 0.10)$. This result is plotted in the comovement box
} 
indicate positive dependence and values below the benchmark indicate negative dependence.

Figure 1 reveals strong evidence of positive dependence for below median (i.e., left tail) returns. For instance, the Quantitative Directional index has a $48 \%$ chance of being in the 10th quantile when the equal-weighted average of the other indices is also in the 10th quantile compared to an unconditional

\section{FIGURE 1}

\section{Monthly Comovement Box: Relations between Individual Hedge Fund Index Performance and the Average of all Other Hedge Fund Indices}

Figure 1 presents the comovement box that plots the estimated probability that the filtered return for a given HFRI index falls below (above) a given quantile, conditional on the average filtered return of the other seven HFRI indices falling below (above) the same quantile for below- (above-) median quantiles. Conditional probabilities for each index are plotted in the unit square box, where the $45^{\circ}$ line (no-dependence benchmark) represents the unconditional probability of no dependence between the variables. Values above (below) the no-dependence benchmark indicate positive (negative) dependence. (Jan. 1994-Dec. 2012, N=228 months)

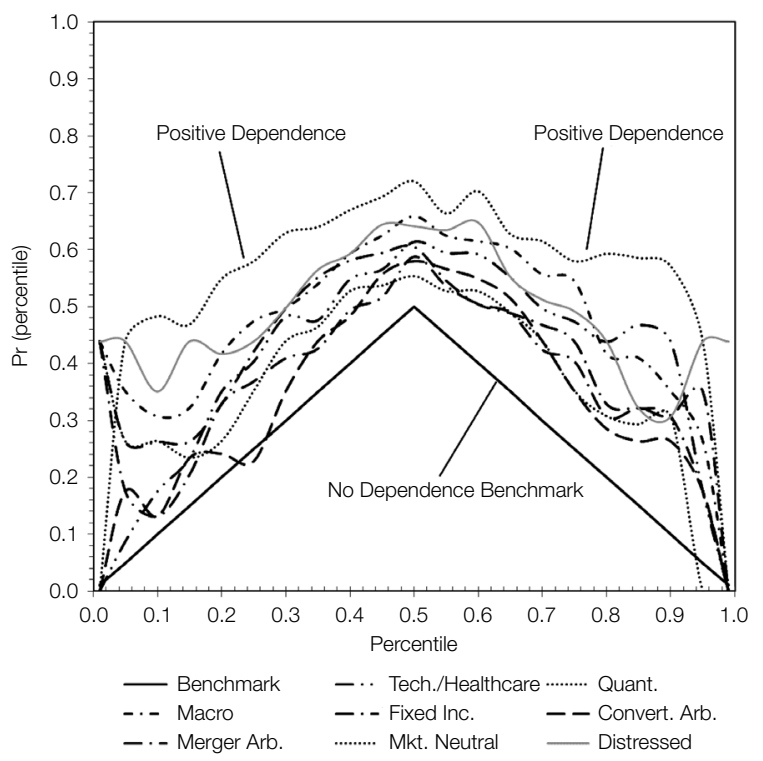

as the "no-dependence benchmark" value for the tenth percentile. Analogously, the benchmark value for the top quintile is the likelihood that two independent variables, $\mathrm{Y}$ and $\mathrm{Z}$, both have realizations in the top quintile divided by the likelihood that $\mathrm{Z}$ has a realization in its upper quintile (i.e., $0.2=$ $(0.2 \times 0.2 /(1-0.80)))$. Thus, the no-dependence benchmark is simply a 45 -degree line to the midpoint of the comovement box that reverses slope beyond the median as it returns to the bottom right-hand corner. Now consider a sample that consists of (for simplicity) 100 monthly returns for a given hedge fund index and for the average of the other seven indices. If these two series are independent, we expect only 1 month where both series are in the bottom decile (i.e., $0.10 \times 0.10 \times 100$ ). Instead, assume we observe 5 months where both series have bottom decile returns. We then compute the fraction of observations where both series are in the bottom decile (5/100), divide by the decile likelihood $(0.10)$, and plot the resulting value of $0.50(=0.05 / 0.10)$ on the vertical axis. In this case, the estimated dependence $(0.50)$ far exceeds the result expected under independence (i.e., the 0.10 benchmark described above). Analogously, if both series have returns in the top quintile in 7 of the same months, the estimated dependence plotted in the comovement box is 0.35 (i.e., $(7 / 100) /(1-0.80)$ at the 0.8 value for the horizontal axis of the comovement box). 
(i.e., no-dependence benchmark) likelihood of only $10 \%$. Inconsistent with the hypothesis that liquidity shock induced hedge fund contagion meaningfully contributes to the dependence, we find no evidence that filtered hedge fund return dependence is asymmetric and limited to the left (poor performance) tail. Consistent with the model misspecification explanation, however, the figure appears largely symmetric.

To formally examine the null hypothesis that joint probabilities from the left side of the comovement box are equal to probabilities from the right side, we report Wald $\chi^{2}$ tests (see Cappiello et al. (2010)) for two hypotheses: i) whether every fifth percentile for below-median probabilities differs meaningfully from the corresponding above-median value (symmetry) and ii) whether the 10th percentile differs meaningfully from the 90th percentile (tail symmetry). ${ }^{7} \chi^{2}$ statistics and associated $p$-values are reported in Table 2 . The results reveal no evidence of meaningful asymmetry in monthly hedge fund index filtered return clustering. ${ }^{8}$

To more fully depict the observed dependence, Figure 2 plots the number of HFRI indices with top (plotted as positive values) or bottom (plotted as negative values) decile filtered returns each month. Figure 2 reveals there is no obvious greater clustering in left tail returns than right tail returns. For example, 9 months have at least four indices with top decile returns and 7 months have at least four indices with bottom decile returns. In addition, inconsistent with the hypothesis that liquidity shock induced contagion primarily drives the dependence in filtered hedge fund returns, much of the clustering in both negative and positive filtered returns occurs during the financial crisis.

TABLE 2

Tests for Asymmetry in Quantile Regressions

The first row in Table 2 reports Wald $\chi^{2}$ statistics and associated $p$-values for the null hypothesis that below-median clustering does not differ from above-median clustering $\left(H_{0}:\right.$ symmetry). The test is based on comparisons of each below-median 5 th quantile with each corresponding above-median 5 th quantile (i.e., 5 th $=95$ th, 10 th $=90$ th, $\ldots, 40$ th $=60$ th , and 45 th $=55$ th $)$. The second row reports analogous statistics for the null hypothesis that clustering at the 10th percentile does not differ from clustering at the 90th percentile ( $H_{0}$ : tail symmetry). Reported values are based on the HFRI indices for 228 months.

\begin{tabular}{|c|c|c|c|c|c|c|c|c|}
\hline & $\begin{array}{l}\text { Equity } \\
\text { Market } \\
\text { Neutral }\end{array}$ & $\begin{array}{c}\text { Quant. } \\
\text { Directional }\end{array}$ & $\begin{array}{c}\text { Tech./ } \\
\text { Healthcare }\end{array}$ & $\begin{array}{l}\text { Distressed } \\
\text { Securities }\end{array}$ & $\begin{array}{c}\text { Merger } \\
\text { Arbitrage }\end{array}$ & Macro & $\begin{array}{l}\text { Convert. } \\
\text { Arbitrage }\end{array}$ & $\begin{array}{c}\text { Fixed } \\
\text { Income } \\
\text { Corporate }\end{array}$ \\
\hline $\begin{array}{l}H_{0}: \text { Symmetry } \\
\text { ( } p \text {-value) }\end{array}$ & $\begin{array}{c}5.75 \\
(0.77)\end{array}$ & $\begin{array}{c}4.53 \\
(0.88)\end{array}$ & $\begin{array}{c}6.99 \\
(0.64)\end{array}$ & $\begin{array}{c}7.41 \\
(0.60)\end{array}$ & $\begin{array}{c}6.76 \\
(0.67)\end{array}$ & $\begin{array}{c}3.33 \\
(0.95)\end{array}$ & $\begin{array}{c}6.65 \\
(0.68)\end{array}$ & $\begin{array}{c}2.86 \\
(0.97)\end{array}$ \\
\hline $\begin{array}{l}H_{0} \text { : Tail symmetry } \\
\text { ( } p \text {-value) }\end{array}$ & $\begin{array}{c}0.08 \\
(0.79)\end{array}$ & $\begin{array}{c}0.17 \\
(0.69)\end{array}$ & $\begin{array}{l}2.60 \\
(0.11)\end{array}$ & $\begin{array}{c}0.07 \\
(0.80)\end{array}$ & $\begin{array}{c}1.61 \\
(0.21)\end{array}$ & $\begin{array}{c}0.07 \\
(0.80)\end{array}$ & $\begin{array}{c}1.00 \\
(0.32)\end{array}$ & $\begin{array}{c}0.08 \\
(0.79)\end{array}$ \\
\hline
\end{tabular}

\footnotetext{
${ }^{7}$ Specifically, the test for symmetry examines nine restrictions under the null hypothesis (the 5th percentile equals the 95th percentile, the 10th percentile equals the 90th percentile, the 15th percentile equals the 85th percentile, and so on, including the final restriction that the 45 th percentile equals the 55th percentile). To examine tail symmetry, we test if the joint probability that both series are less than 0.1 equals the joint probability that both series are greater than 0.9 .

${ }^{8}$ In untabulated analysis, we also test the following: i) whether the 5th percentile differs from the 95th percentile, ii) whether the 15th percentile differs from the 85th percentile, iii) whether the 20 th percentile differs from the 80th percentile, iv) whether the 25 th percentile differs from the 75 th percentile, and v) whether every 5th percentile between the 5th and 25th percentiles differs from clustering in the analogous right tail percentiles (i.e., 5 th $=95$ th, 10 th $=90$ th, $\ldots, 25$ th $=75$ th). In no case can we reject the hypothesis of symmetry even at the $10 \%$ level.
} 
FIGURE 2

Number of Hedge Fund Indices with Top and Bottom Decile Filtered Returns over Time

Figure 2 plots the number of the eight HFRI indices having top (reported as positive values) and bottom (reported as negative values) decile filtered returns each month. (Jan. 1994-Dec. 2012, N=228 months)

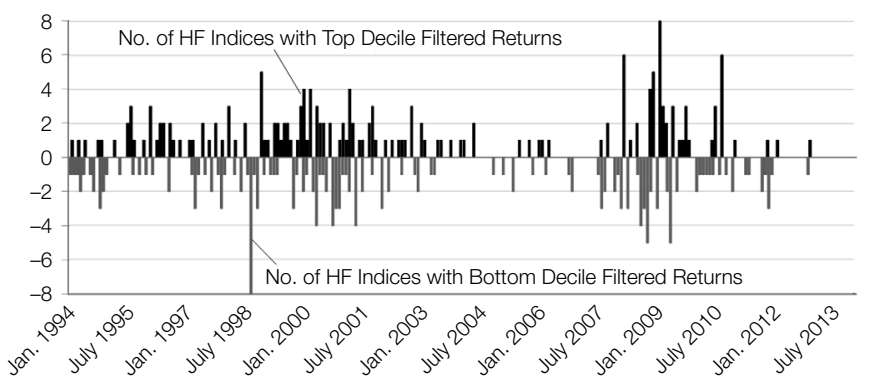

To provide a formal test for whether the levels of clustering are meaningfully different from 0 , we compute the likelihood that at least $K$ hedge fund indices experience bottom (or top) decile filtered returns in any given month. For instance, the likelihood that at least four of the eight hedge fund indices would experience bottom decile returns in any given month is 0.00502. ${ }^{9}$ Thus, out of 228 months, we expect 1 month (i.e., $0.00502 \times 228=1.15$ ) where at least four of the indices have bottom decile returns (assuming independence). The first row of Table 3 reports these expected values (under the null of independence). The second and third rows report the observed number of months with $K$ or more hedge fund indices exhibiting bottom and top decile filtered returns, respectively. We also report (parenthetically) $p$-values from binomial tests of the null hypothesis that the number of observed months with $K$ or more filtered returns in the top (or bottom) decile does not differ from the expected values reported in the top row. ${ }^{10}$ Consistent with the comovement box and related Table 2 inferences, the results in Table 3 reveal strong evidence that clustering levels (statistically significant at the $1 \%$ level) are far above expected values in both the right and left tails.

In sum, the results in this section reveal that filtered hedge fund index returns exhibit substantial dependence. There is no evidence, however, that the dependence is asymmetric. The results are consistent with the hypothesis that model misspecification explains the observed dependence in filtered hedge fund returns

\footnotetext{
${ }^{9}$ This is the binomial probability that $4,5,6,7$, or 8 funds have bottom decile returns in a given month assuming independence. For instance, the likelihood that four indices have bottom decile returns in a given month is given by $p(4$ of 8$)=\left(8 ! /(4 !(8-4) !) 0.1^{4}(1-0.1)^{8-4}\right)$. The probability of at least 4 is $p(4$ of 8$)+p(5$ of 8$) \ldots+p(8$ of 8$)$.

${ }^{10}$ For instance, the probability (under the null hypothesis of independence) that we would observe at least 7 months where four or more indices experience bottom decile returns (i.e., $K \geq 4$ ) the same month is less than 0.001 . This is the binomial probability of $7,8,9, \ldots$, or 228 months with at least 4 funds having bottom decile returns the same month assuming independence. That is, the probability of observing 7 months is given by $p(7$ of 228$)=\left(228 ! /(7 !(228-7) !) 0.00502^{7}(1-0.00502)^{228-7}\right)$, where 0.00502 is the probability of observing at least 4 funds with bottom decile returns in any given month. The probability of at least 7 months where at least four indices have bottom decile returns is $p(7$ of $228)+p(8$ of 228$) \ldots+p(228$ of 228$)$.
} 
TABLE 3

Number of Months When More than $K$ Hedge Fund Indices Have Bottom (or Top) Decile Filtered Returns

The first row in Table 3 reports the expected number of months when at least $K$ of the eight monthly hedge fund indices would exhibit bottom and top decile filtered returns the same month under the null hypothesis of independence. For instance, under the null of independence, we expect to observe approximately 1 month (of the 228 months in our sample) where at least four $(K \geq 4)$ indices have top decile returns and 1 month where at least four indices have bottom decile returns. The next two rows report the observed number of months where at least $K$ of the eight hedge fund indices have bottom and top decile returns, respectively, and associated $p$-values computed from the binomial probabilities under the null hypothesis of independence.

\begin{tabular}{|c|c|c|c|c|c|c|}
\hline & $K \geq 3$ & $K \geq 4$ & $K \geq 5$ & $K \geq 6$ & $K \geq 7$ & $K=8$ \\
\hline $\begin{array}{l}\text { Expected number of months } \\
\text { Observed number of months }\end{array}$ & 8.68 & 1.15 & 0.10 & 0.005 & 0.0002 & $<0.0001$ \\
\hline $\begin{array}{l}\text { Bottom decile returns } \\
\text { ( } p \text {-value) }\end{array}$ & $\begin{array}{c}21 \\
(0.01)\end{array}$ & $\begin{array}{c}7 \\
(0.01)\end{array}$ & $\begin{array}{c}3 \\
(0.01)\end{array}$ & $\begin{array}{c}1 \\
(0.01)\end{array}$ & $\begin{array}{c}1 \\
(0.01)\end{array}$ & $\begin{array}{c}1 \\
(0.01)\end{array}$ \\
\hline $\begin{array}{l}\text { Top decile returns } \\
\text { ( } p \text {-value) }\end{array}$ & $\begin{array}{c}20 \\
(0.01)\end{array}$ & $\begin{array}{c}9 \\
(0.01)\end{array}$ & $\begin{array}{c}5 \\
(0.01)\end{array}$ & $\begin{array}{c}3 \\
(0.01)\end{array}$ & $\begin{array}{c}1 \\
(0.01)\end{array}$ & $\begin{array}{c}1 \\
(0.01)\end{array}$ \\
\hline
\end{tabular}

and inconsistent with the hypothesis that liquidity spirals meaningfully contribute to the observed dependence in filtered hedge fund index returns.

\section{B. Dependence with the Short Bias Index}

Expected residual correlations (and, therefore, filtered hedge fund return dependence) will be nonzero if $i)$ the model is missing a factor, ii) factors are measured with error (i.e., partially misspecified), iii) there is a common component to time-varying factor exposures, or iv) manager behavior or illiquid assets lead to return smoothing (we provide a development in our accompanying Internet Appendix). That is, the model misspecification problem is not limited to missing factors. Intuitively, if the model is misspecified for any reason, the dependence is forced into the residuals. Given the strong condition of a perfectly specified factor model with no return smoothing that perfectly estimates time-varying factor loadings, it is unlikely one could ever fully eliminate the residual dependence across hedge fund indices.

We next consider a direct test of whether the dependence depicted in Figure 1 is attributed to the Brunnermeier and Pedersen (2009) liquidity spiral explanation versus the model misspecification explanation by examining the relation between filtered returns for the HFRI monthly Short Bias index and the other HFRI indices in our sample. Our motivation for this test comes from two properties. First, although missing factors, misspecified factors, time-varying factor exposures, or return smoothing produce nonzero residual dependence, they do not necessarily induce positive dependence in filtered returns. Specifically, the sign of the residual correlation will depend on the signs of the factor loadings (see the Internet Appendix for proof). If the factor loadings for two hedge fund indices have the same sign for the misspecified or missing factor (or if the two indices have the same sign for a time-varying factor loading), their residual correlation will be positive. Alternatively, if the factor loadings for two hedge fund indices have opposite signs, the residual correlation will be negative.

Second, within the Brunnermeier and Pedersen (2009) model, hedge funds will be long undervalued stocks (that customers are selling) and short overvalued stocks (that customers are buying). In a liquidity crisis, undervalued stocks (where 
hedge funds are long) become more undervalued and overvalued stocks (where hedge funds are short) become more overvalued. In short, a liquidity spiral causes hedge fund losses in both their long and short positions.

These two properties provide a clean test of whether the hedge fund filtered return dependence reported in Figure 1 primarily arises from Brunnermeier and Pedersen (2009) liquidity shock induced contagion or model misspecification. Specifically, relative to the average of the other indices, Short Bias fund loadings will exhibit the opposite sign on economic fundamentals but the same sign on liquidity shock induced contagion. Thus, if hedge fund filtered return dependence primarily results from liquidity shock induced contagion, the residual correlation between the Short Bias index and the remaining indices will be positive for left tail returns and independent for right tail returns (a positive asymmetric relation). Alternatively, if the dependence results from model misspecification, then the Short Bias index filtered returns will exhibit negative dependence with the other indices in both tails (a negative symmetric relation).

Figure 3 presents the monthly filtered return comovement box for the Short Bias HFRI index versus the average of the other eight monthly indices. The results reveal strong negative dependence between the filtered Short Bias index and the average filtered return across the other eight HFRI indices. The correlation (untabulated) between the Short Bias filtered return and the average filtered return across the other eight indices is $-48 \%$ (statistically significant at the $1 \%$ level).

\section{FIGURE 3}

\section{Monthly Comovement Box for the Short Bias Index}

Figure 3 presents the comovement box that plots the estimated probability that the filtered return for the HFRI Short Bias index falls below (above) a given quantile, conditional on the average filtered return of the other eight HFRI indices falling below (above) the same quantile for below- (above-) median quantiles. Conditional probabilities are plotted in the unit square box, where the $45^{\circ}$ line (no-dependence benchmark) represents the unconditional probability of no dependence between the variables. Values above (below) the no-dependence benchmark indicate positive (negative) dependence. (Jan. 1994-Dec. 2012, N=228 months)

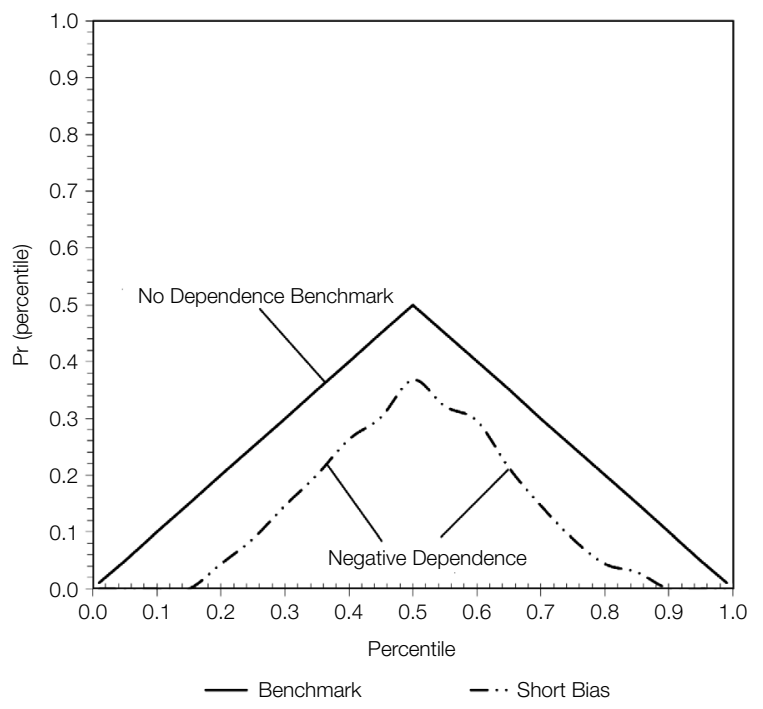


The negative symmetric relation, rather than an asymmetric positive relation, suggests again that model misspecification, rather than liquidity spirals, primarily drives the dependence in filtered hedge fund returns. ${ }^{11}$

\section{Hedge Fund Filtered Return Dependence and Liquidity Channel Shocks}

The liquidity shock induced contagion hypothesis implies that negative liquidity shocks should be positively related to the likelihood of observing left tail filtered return clustering but inversely related to the likelihood of observing right tail filtered return clustering. The model misspecification explanation also suggests, however, that negative liquidity shocks will be associated with filtered return clustering. Specifically, if negative liquidity shocks are more likely when fundamental volatility is large and the factor model is less than perfectly specified, then negative liquidity shocks will be positively associated with the likelihood of observing clustering in both the right and left tails. That is, one is more likely to observe both extreme filtered returns (assuming a less than perfectly specified model) and negative liquidity shocks when fundamental volatility is high.

Thus, we consider three tests in this section. First, we test whether negative liquidity shocks are more likely to occur when fundamental volatility is high. Second, we examine the relation between negative liquidity shocks and the likelihood of observing clustering in both the left and right tails. Third, we add a proxy for fundamental volatility to the model to test if the relation between negative liquidity shocks and tail clustering remains intact when controlling for fundamental volatility.

Our tests require measures of both negative liquidity shocks and fundamental volatility. We use market volatility (the natural logarithm of the standard deviation

\footnotetext{
${ }^{11}$ These Short Bias index related inferences might be naturally extended to suggest that the residual correlation for the Equity Market Neutral index should be close to 0 under the model misspecification explanation. Unfortunately, it is well recognized that, despite their moniker, market neutral funds average significant positive market exposures (e.g., Patton (2009)). Nonetheless, we do find that the filtered return correlation between the HFRI Equity Market Neutral index and the average of the other seven original indices is the lowest of the group ( 0.19 vs. 0.27 on average for the other seven, untabulated), further consistent with the model misspecification explanation. Note that this argument is also inconsistent with the Brunnermeier and Pedersen (2009) model, as a market neutral fund is long undervalued stocks and short overvalued stocks and, during a liquidity spiral, should experience losses in both its long and short positions. One may also propose that perhaps hedge funds are liquidity providers in their long positions but not in their short positions. That argument, however, is also inconsistent with the Brunnermeier and Pedersen model. Finally, it is possible that Short Bias hedge funds take offsetting positions relative to other hedge funds such that a liquidity crisis benefits Short Bias funds as net long funds quickly delever and liquidate positions. That scenario, however, is also inconsistent with the Brunnermeier and Pedersen hedge fund liquidity spiral model. One could also propose that all security prices decline (regardless of whether hedge funds are long or short in the security) during a liquidity crisis. Although possible, that too is inconsistent with Brunnermeier and Pedersen's model, as that argument suggests prices of overvalued securities (where hedge funds are short by providing liquidity to customers who are buying the overvalued stocks) move toward fundamental values during a liquidity crisis, while prices of undervalued securities (where hedge funds are long by providing liquidity to customers who are selling the undervalued stocks) move away from fundamental values during a liquidity crisis. In sum, the negative relation between filtered Short Bias index returns and the filtered returns of other hedge fund indices supports the model misspecification explanation but is inconsistent with the liquidity spiral mechanisms in the Brunnermeier and Pedersen model.
} 
of daily returns in month $t$ scaled to annual magnitude) as a measure of fundamental volatility, given extant work demonstrates that volatility in underlying economic conditions drives much of the time-series variation in market volatility. For example, Engle, Ghysels, and Sohn (2013) find macroeconomic sources explain approximately half of the time-series variation in market volatility. For the liquidity metrics, we focus on innovations in eight liquidity channel contagion variables (the first six are based on those used by Boyson et al. (2010); the last two were suggested by the referee): the percent change in the credit spread, percent change in the Treasury-Eurodollar (TED) spread, Pastor and Stambaugh (2003) innovations in the aggregate stock liquidity variable, bank return index, prime broker return index, percent change in Repo volume, Amihud (2002) stock illiquidity measure, and Sadka (2006) stock liquidity measure. With the exception of the Pastor and Stambaugh factor and the Sadka factor (which are prewhitened), we remove autocorrelation from each series with estimation of an autoregressive (AR(1)) process. Further, following Boyson et al. (2010), we define a negative liquidity shock as a bottom quartile realization (e.g., a large increase in the TED spread or a low return for prime brokers). The Internet Appendix provides details regarding the source and construction of each channel variable, along with related descriptive statistics.

We begin by examining whether negative liquidity shocks are more likely to be observed in periods of high fundamental volatility. Specifically, we estimate a logit for each of the eight channel variables, where the dependent variable is 1 if the liquidity channel variable is in its bottom quartile realization and 0 otherwise, and the independent variable is market volatility. For brevity, we report detailed results in the Internet Appendix. The results are consistent with our hypothesis. Specifically, market volatility is strongly (statistically significant at the 5\% level or better) positively related to bottom liquidity quartile realizations for six of the eight channel variables. For these six channel variables, the estimated likelihood (on average) of observing a bottom quartile realization increases from $13.4 \%$ to $36.4 \%$ when realized market volatility changes from 1 standard deviation below its mean to 1 standard deviation above its mean (untabulated). ${ }^{12}$

We next examine the relation between negative liquidity shocks and the likelihood of observing clustering in both the left and right tails. Specifically, both the liquidity spiral and model misspecification explanations suggest that negative liquidity shocks should be associated with a greater likelihood of observing left tail clustering. However, the hypotheses have contrary predictions for right tail clustering. The liquidity spiral explanation predicts that negative liquidity shocks should be associated with a lower likelihood of observing right tail clustering. In contrast, given the above tests reveal negative liquidity shocks are more likely when fundamental volatility is high, the model misspecification explanation implies a positive relation between negative liquidity shocks (as a proxy for periods of high fundamental volatility) and the likelihood of observing right tail filtered return clustering.

\footnotetext{
${ }^{12}$ Moreover, the time-series correlation between the number of filtered index returns with top or bottom decile returns and market volatility is 0.51 (statistically significant at the $1 \%$ level, untabulated).
} 
Our empirical specification for these tests builds on the work of Boyson et al. (2010) who examine whether negative liquidity shocks are associated with an increased likelihood of left tail filtered return clustering. ${ }^{13}$ We extend these tests, however, by examining the relation between negative liquidity shocks and both left and right tail clustering. Specifically, we estimate multinomial logits that define the base case of no clustering as months where fewer than three hedge fund indices experience simultaneous right tail (top decile) or left tail (bottom decile) filtered returns. The alternative cases are right tail clustering months when three or more indices have top decile filtered returns and left tail clustering months when three or more indices have bottom decile filtered returns. ${ }^{14}$ For each channel variable, the independent variables include an intercept, the channel variable winsorized at the 25th percentile of bad outcomes, and an indicator for bottom quartile channel realizations (i.e., a negative liquidity shock). ${ }^{15}$

The multinomial logit results (reported in Table 4) provide evidence that negative liquidity shocks are associated with an increase in the likelihood of observing left tail clustering as four of the eight coefficients associated with the liquidity shock indicator variables are meaningfully positive (at the 5\% level or better) for the left tail logit. However, contrary to the liquidity spiral hypothesis, but consistent with the model misspecification explanation, we also find that negative shocks to four of the eight channel variables are associated with a greater, rather than lesser, likelihood of observing right tail clustering (statistically significant at the $5 \%$ level or better). The second from bottom row reports $p$-values from a Wald $\chi^{2}$ test that the left and right tail coefficients associated with negative liquidity shocks are equal. There is no evidence that the relation between negative liquidity shocks and the likelihood of clustering in the left tail differs meaningfully from the likelihood of clustering in the right tail for any of the eight channel variables.

To gauge the economic significance of the results, we compute (untabulated) predicted probabilities for normal and shock periods (i.e., mean and bottom quartile realizations of the channel variables). On average, across the eight indicators, we find the probability of right tail clustering is $5.5 \%$ and left tail clustering is $6.2 \%$ during normal periods. In comparison, during negative liquidity shock periods, we find the average probability of right and left tail clustering is $16.8 \%$ and $15.4 \%$, respectively.

If negative liquidity shocks are positively related to clustering in both tails because negative liquidity shocks proxy for periods of high fundamental volatility

\footnotetext{
${ }^{13}$ Two of our tests build on the work of Boyson et al. (2010) and the related interpretation of this work in Boyson and Stahel (2010) and Boyson, Stahel, and Stulz (2012). In contrast to our work, they find strong evidence of asymmetry in filtered monthly hedge fund returns. Unfortunately, this evidence results from an error in their computation of the comovement box. Our Internet Appendix provides a more complete reconciliation with the results reported in these works.

${ }^{14} \mathrm{We}$ adopt clustering definitions that ensure each observation is characterized as a right tail clustering month, a left tail clustering month, or base case observation. One month (Apr. 2000) has at least three hedge fund indices with filtered returns in both the top and bottom deciles. We define this month as a "base" case.

${ }^{15}$ As detailed in the Internet Appendix, we multiply the Amihud measure, changes in credit spreads, and change in the TED spread by -1 such that an increase in any of the eight channel variables represents an improvement in liquidity.
} 
Table 4 reports results from multinomial logistic regressions of hedge fund return clustering. The dependent variable is defined as the outcome of a variable $\left(O C C U R_{t}\right)$ that takes the value of 0 if fewer than three (of eight) hedge fund indices have simultaneous top or bottom decile filtered returns in a given month (base case), 1 if three or more hedge fund indices have a bottom decile filtered return during a given month (left), and 2 if three or more hedge fund indices have a top decile (right) filtered return in a given month. Each model includes the continuous channel variable winsorized at the 25th percentile of worst outcomes and an indicator variable identifying months in the bottom quartile of outcomes (e.g., a large increase in the credit spread or a low bank index return). The liquidity channel variables include the following: the percentage change in Credit Spread (CRSPRD), percentage change in the Treasury-Eurodollar spread (TED), Pastor and Stambaugh (2003) Liquidity innovation (PSLIQ), monthly return to the KBW Bank Index (BANK), monthly return to the Prime Broker Index (PBI), monthly percent change in Repo volume (REPO), Amihud (2002) stock illiquidity measure (AMIHUD), and Sadka (2006) stock liquidity measure (SADKA). We report $p$-values in parentheses below coefficient estimates. The row following the indicator variable coefficients reports $p$-values for a $\chi^{2}$ test of whether the coefficients associated with negative liquidity shocks are equal for the right and left tails. $R^{2}$-Max is the scaled coefficient of determination suggested by Nagelkerke (1991). Coefficients with * and ${ }^{* *}$ are statistically significant at the $5 \%$ and $1 \%$ levels, respectively. All contagion variables (except REPO) include 227 observations from Feb. 1994 through Dec. 2012. The Repo data covers Sept. 2001-Dec. 2012 (136 observations).

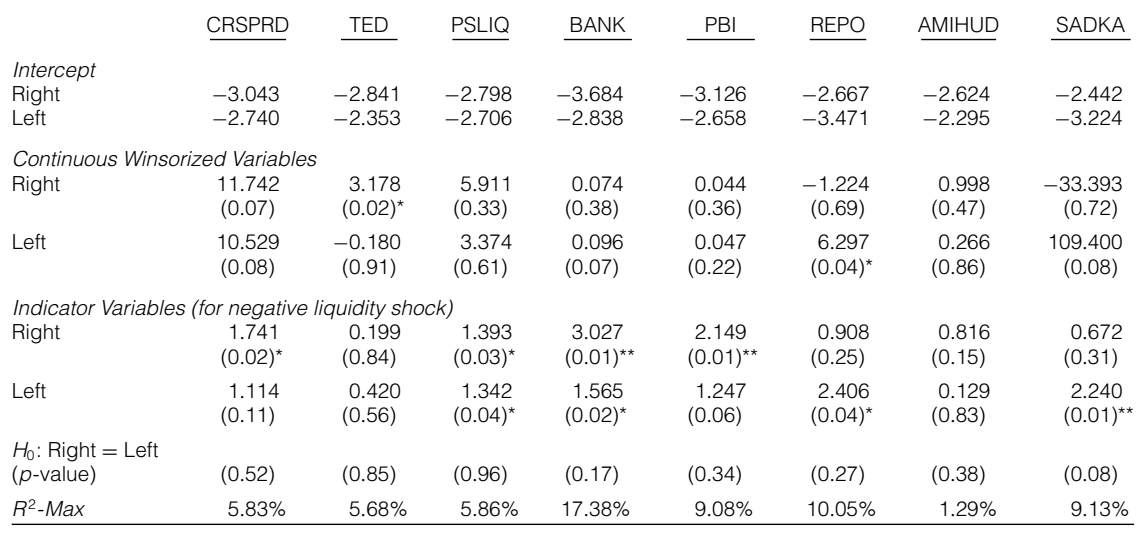

and the model is misspecified, then the likelihood of clustering in either tail should be positively related to market volatility (as a measure of fundamental volatility). To explore this hypothesis, we repeat the multinomial logits examining the relation between negative liquidity shocks and clustering but add market volatility as an explanatory variable. The results, reported in Table 5, reveal that, in every case, higher market volatility is strongly related to a greater likelihood of both right and left tail filtered hedge fund index clustering (statistically significant at the $1 \%$ level in all cases). That is, hedge fund filtered returns cluster in turbulent market environments when model misspecification problems are most likely. In addition, we never reject the hypothesis that the relation between market volatility and clustering in the left tail meaningfully differs from the relation between market volatility and right tail clustering. Moreover, only 2 of 16 negative liquidity shock indicators retain statistical significance at the 5\% level (one in each tail), and we can never reject the hypothesis that negative liquidity shocks impact the left and right tails equally. ${ }^{16}$

\footnotetext{
${ }^{16}$ Again we compute predicted probabilities to gauge the economic magnitude of the results. Across the eight indicators, the mean volatility and channel variable realizations yield a probability of right tail clustering of $4.6 \%$ and left tail clustering of $5.3 \%$, on average. Given mean volatility and a bottom quartile channel variable realization, the average probability of right and left tail clustering is $9.4 \%$ and $8.0 \%$, respectively. In contrast, the average probability of right and left tail clustering given a top volatility quartile and a mean channel realization is $20.2 \%$ and $23.0 \%$, respectively.
} 
TABLE 5

Negative Shocks to Liquidity Channel Variables, Market Volatility, and Hedge Fund Dependence

Table 5 reports results from multinomial logistic regressions of hedge fund return clustering. The dependent variable is defined as the outcome of a variable (OCCUR $)$ that takes the value of 0 if fewer than three (of eight) hedge fund indices have simultaneous top or bottom decile filtered returns in a given month (base case), 1 if three or more hedge fund indices have a bottom decile filtered return during a given month (left), and 2 if three or more hedge fund indices have a top decile (right) filtered return in a given month. Each model includes three independent variables: the continuous channel variable winsorized at the 25 th percentile of worst outcomes, an indicator variable identifying months in the bottom quartile of outcomes (e.g., a large increase in the credit spread or a low bank index return), and the natural logarithm of the annualized standard deviation of market excess returns (computed from daily returns within the month). The liquidity channel variables include the following: the percentage change in Credit Spread (CRSPRD), percentage change in the Treasury-Eurodollar spread (TED), Pastor and Stambaugh (2003) Liquidity innovation (PSLIQ), monthly return to the KBW Bank Index (BANK), monthly return to the Prime Broker Index (PBI), monthly percent change in Repo volume (REPO), Amihud (2002) stock illiquidity measure (AMIHUD), and Sadka (2006) stock liquidity measure (SADKA). We report $p$-values in parentheses below coefficient estimates. We also report $p$-values for $\chi^{2}$ tests of whether the coefficients associated with negative liquidity shocks or market volatility are equal for the right and left tails. $R^{2}-$ Max is the scaled coefficient of determination suggested by Nagelkerke (1991). Coefficients with ** and * are statistically significant at the $1 \%$ and $5 \%$ levels, respectively. All contagion variables (except REPO) include 227 observations from Feb. 1994 through Dec. 2012. The Repo data covers Sept. 2001-Dec. 2012 (136 observations).

\begin{tabular}{|c|c|c|c|c|c|c|c|c|}
\hline & CRSPRD & TED & PSLIQ & BANK & PBI & REPO & AMIHUD & $\underline{\text { SADKA }}$ \\
\hline \multicolumn{9}{|l|}{ Intercept } \\
\hline Right & 0.817 & 1.533 & 1.095 & -0.467 & 0.433 & 3.829 & 1.357 & 2.152 \\
\hline Left & 1.602 & 1.756 & 1.449 & 1.500 & 2.015 & 1.607 & 2.320 & 0.626 \\
\hline \multicolumn{9}{|c|}{ Continuous Winsorized Variables } \\
\hline Right & $\begin{array}{l}9.935 \\
(0.13)\end{array}$ & $\begin{array}{l}3.555 \\
(0.01)^{\star \star}\end{array}$ & $\begin{array}{c}4.123 \\
(0.50)\end{array}$ & $\begin{array}{c}0.036 \\
(0.66)\end{array}$ & $\begin{array}{c}0.012 \\
(0.79)\end{array}$ & $\begin{array}{c}-2.654 \\
(0.47)\end{array}$ & $\begin{array}{c}0.483 \\
(0.75)\end{array}$ & $\begin{array}{r}-104.100 \\
(0.26)\end{array}$ \\
\hline Left & $\begin{array}{c}8.684 \\
(0.15)\end{array}$ & $\begin{array}{l}0.519 \\
(0.74)\end{array}$ & $\begin{array}{l}1.614 \\
(0.81)\end{array}$ & $\begin{array}{c}0.039 \\
(0.47)\end{array}$ & $\begin{array}{l}0.002 \\
(0.95)\end{array}$ & $\begin{array}{l}6.109 \\
(0.09)\end{array}$ & $\begin{array}{c}-0.479 \\
(0.77)\end{array}$ & $\begin{array}{l}52.722 \\
(0.43)\end{array}$ \\
\hline \multicolumn{9}{|c|}{ Indicator Variables (for negative liquidity shock) } \\
\hline Right & $\begin{array}{l}1.143 \\
(0.13)\end{array}$ & $\begin{array}{c}0.013 \\
(0.99)\end{array}$ & $\begin{array}{l}0.765 \\
(0.26)\end{array}$ & $\begin{array}{l}2.329 \\
(0.01)^{\star \star}\end{array}$ & $\begin{array}{c}1.218 \\
(0.11)\end{array}$ & $\begin{array}{c}0.965 \\
(0.32)\end{array}$ & $\begin{array}{r}0.287 \\
(0.64)\end{array}$ & $\begin{array}{c}-0.500 \\
(0.52)\end{array}$ \\
\hline Left & $\begin{array}{c}0.436 \\
(0.55)\end{array}$ & $\begin{array}{l}0.381 \\
(0.61)\end{array}$ & $\begin{array}{l}0.671 \\
(0.32)\end{array}$ & $\begin{array}{l}0.520 \\
(0.48)\end{array}$ & $\begin{array}{c}-0.085 \\
(0.91)\end{array}$ & $\begin{array}{l}2.678 \\
(0.03)^{\star}\end{array}$ & $\begin{array}{r}-0.554 \\
(0.41)\end{array}$ & $\begin{array}{r}1.321 \\
(0.08)\end{array}$ \\
\hline $\begin{array}{l}H_{0}: \text { Right }=\text { Left } \\
(p \text {-value })\end{array}$ & $(0.46)$ & $(0.75)$ & $(0.92)$ & $(0.10)$ & $(0.19)$ & $(0.23)$ & $(0.31)$ & $(0.07)$ \\
\hline \multicolumn{9}{|l|}{ Market Volatility } \\
\hline Right & $\begin{array}{l}2.066 \\
(0.01)^{\star \star}\end{array}$ & $\begin{array}{l}2.511 \\
(0.01)^{\star \star}\end{array}$ & $\begin{array}{l}2.087 \\
(0.01)^{\star \star}\end{array}$ & $\begin{array}{l}1.640 \\
(0.01)^{\star \star}\end{array}$ & $\begin{array}{l}1.808 \\
(0.01)^{\star \star}\end{array}$ & $\begin{array}{l}4.131 \\
(0.01)^{\star \star}\end{array}$ & $\begin{array}{l}2.143 \\
(0.01)^{* *}\end{array}$ & $\begin{array}{l}2.381 \\
(0.01)^{\star \star}\end{array}$ \\
\hline Left & $\begin{array}{l}2.374 \\
(0.01)^{\star \star}\end{array}$ & $\begin{array}{l}2.384 \\
(0.01)^{\star \star}\end{array}$ & $\begin{array}{l}2.252 \\
(0.01)^{\star \star}\end{array}$ & $\begin{array}{l}2.268 \\
(0.01)^{\star \star}\end{array}$ & $\begin{array}{l}2.436 \\
(0.01)^{\star \star}\end{array}$ & $\begin{array}{l}3.064 \\
(0.01)^{\star \star}\end{array}$ & $\begin{array}{l}2.527 \\
(0.01)^{* *}\end{array}$ & $\begin{array}{l}1.965 \\
(0.01)^{\star \star}\end{array}$ \\
\hline $\begin{array}{l}H_{0}: \text { Right }=\text { Left } \\
(p \text {-value })\end{array}$ & $(0.64)$ & $(0.85)$ & $(0.80)$ & $(0.36)$ & $(0.38)$ & $(0.28)$ & $(0.57)$ & $(0.56)$ \\
\hline$R^{2}-\operatorname{Max}$ & $24.20 \%$ & $27.36 \%$ & $22.93 \%$ & $29.69 \%$ & $24.09 \%$ & $45.30 \%$ & $22.41 \%$ & $24.64 \%$ \\
\hline
\end{tabular}

In sum, the results in this section support the model misspecification explanation. Inconsistent with the liquidity spiral explanation, negative liquidity shocks are associated with a greater likelihood of right tail clustering. ${ }^{17}$ Further consistent with the model misspecification hypothesis, negative liquidity shocks tend to occur when market volatility is high and adding market volatility as an

\footnotetext{
${ }^{17}$ In untabulated analysis, we repeat our tests employing the margin variable used by Dudley and Nimalendran (2011) and the hedge fund flow variable in Boyson et al. (2010). Because we were unable to obtain data for the U.S. dollar/Japanese Yen exchange rates or Eurodollars prior to 2000, we use only the margin for S\&P 500 index futures in the 1994-1999 period (and all three margins for the 2000-2012 period). For our sample period, we find no evidence that negative shocks to margins or hedge fund flows are meaningfully associated with clustering in either the left or right tails or that the coefficients associated with margins (or flows) differ for the left and right tails. Moreover, we continue to find a strong positive relation between market volatility and hedge fund filtered return clustering in both tails when adding market volatility to the model.
} 
explanatory variable subsumes the relation between negative liquidity shocks and the likelihood of observing clustering in either tail.

\section{Equity Size-Sorted Portfolios, Model Misspecification, and Liquidity Shocks}

The Brunnermeier and Pedersen (2009) model predicts that liquidity spirals will occur in assets where speculators provide liquidity to other investors. Although hedge funds may provide liquidity for some equities, it is unlikely they serve as the primary liquidity providers for most stocks. For instance, as noted above, nonhedge fund institutions dominate equity ownership. For instance, by the end of 2012, hedge funds accounted for about $9 \%$ of the average firm's shares versus nearly $50 \%$ of outstanding shares held by other types of institutions. As a result, it is unlikely that hedge fund liquidity spirals could explain these patterns in broad passive equity portfolios relative to hedge fund indices that directly reflect speculator positions and trades. Alternatively, if time-varying volatility and the inability of the linear factor model to fully capture changes in economic conditions impact filtered return dependence, then these empirical regularities may appear in both hedge fund indices and other passive nonhedge fund portfolios. Thus, in this section, we further test if model misspecification and time-varying volatility help explain the patterns in filtered hedge fund index returns by shifting our focus from managed hedge funds to passive equity portfolios. In addition, one potential limitation of the test in the previous section is that market volatility may simply be a better liquidity proxy (e.g., Nagel (2012)). ${ }^{18}$

We begin by computing filtered equal-weighted equity size ranked portfolio returns (raw return data from Ken French's Web site) ${ }^{19}$ from time-series regressions of the equity portfolio returns on the same factors used to control for commonality due to changes in economic fundamentals in the hedge fund analysis (for the same 1994-2012 period). Figure 4 reports the comovement box for the filtered size ranked equity portfolios and reveals strong evidence of positive dependence in both tails, much like hedge fund indices.

We also examine whether the likelihood of observing clustering in the size ranked equity portfolios is related to negative liquidity shocks (analogous to our Table 4 analysis). Consistent with the model misspecification explanation, we find evidence that negative liquidity shocks are associated with an increased probability of observing both left and right tail clustering. Moreover, fully consistent with our hedge fund index results and the model misspecification explanation, we find that market volatility is also strongly related to the likelihood of clustering in size ranked portfolios. Detailed results are reported in the Internet Appendix.

\section{E. Model Misspecification and the Magnitude of Dependence: Simulations}

The proofs in the Internet Appendix demonstrate that model misspecification leads to residual dependence, and our empirical tests support the view that model misspecification, rather than liquidity spirals, is the primary factor underlying hedge fund filtered return dependence. In this section, we provide simulations

\footnotetext{
${ }^{18}$ See Schwert (1989) for a brief review of related literature discussing sources of market volatility.

${ }^{19}$ Available at http://mba.tuck.dartmouth.edu/pages/faculty/ken.french/data_library.html
} 
FIGURE 4

Monthly Comovement Box: Relations between Monthly Equity Size Ranked Portfolio Filtered Returns

Figure 4 presents the comovement box that plots the estimated probability that the filtered return for a given size ranked portfolio falls below (above) a given quantile, conditional on the average filtered return of the other nine indices falling below (above) the same quantile for below- (above-) median quantiles. Conditional probabilities for each index are plotted in the unit square box, where the $45^{\circ}$ line (no-dependence benchmark) represents the unconditional probability of no dependence between the variables. Values above (below) the no-dependence benchmark indicate positive (negative) dependence. (Jan. 1994-Dec. 2012, N=228 months)

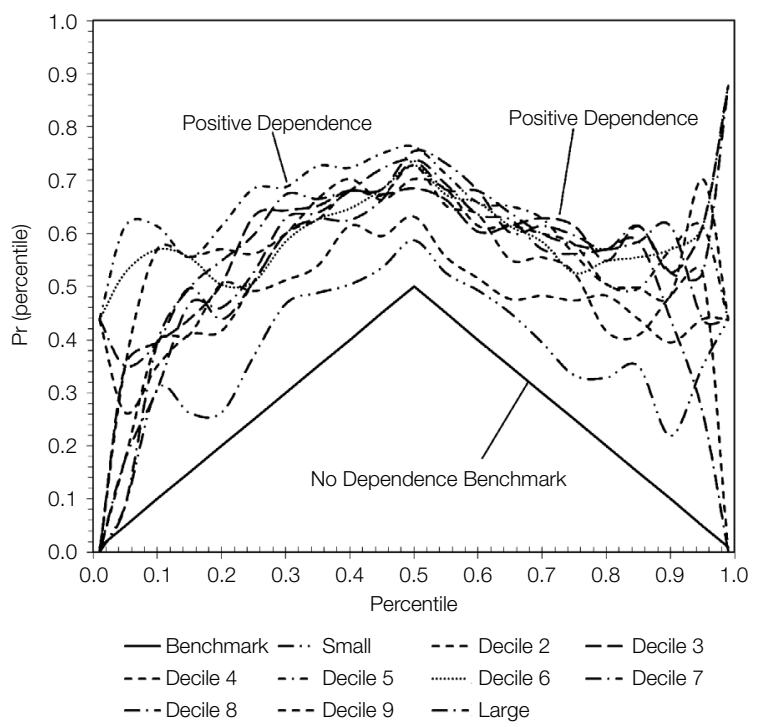

under different scenarios to gauge the degree of model misspecification required to generate the dependence we observe and ensure that non-normalities in filtered hedge fund returns (see Table 1) do not meaningfully impact our conclusions.

Our goal is to simulate data that resemble the non-normalities found in the hedge fund data. We begin with a single factor base case. To ensure the factor's distribution resembles the actual return generating process, we use the empirical distribution of the first principal component from the eight HFRI indices to form a random variable that exhibits similar non-normalities. We then use the coefficient from a regression of each HFRI index on the first principal component as the factor loading for each simulated index. ${ }^{20}$ Similarly, we create index-specific shocks for each of the eight indices that match the empirical moments of filtered returns reported in Table 1. Thus, the simulated base case return for index $i$ in month $t$ is computed as

$$
r_{i t}=\gamma_{i 1} F_{1 t}+e_{i t},
$$

where, by construction, the systematic shock $\left(F_{1 t}\right)$ is independent of the indexspecific shock $\left(e_{i t}\right)$ and the index-specific shocks are independent across the eight indices. We create 1,000 replications of each base case simulation with 228

\footnotetext{
${ }^{20}$ Specifically, we use the Fleishman (1978) cubic polynomial transformation to match the empirical distributions.
} 
months per simulation (to match the sample period from 1994 to 2012). In sum, we generate 228,000 observations for the explanatory variable $\left(F_{1 t}\right)$ and each of the eight index-specific shocks $\left(e_{i t}\right)$.

This approach yields a number of attractive properties. First, the distributions for the simulated filtered returns closely match the filtered return distributions in the data. Second, the framework allows the model fit to vary across the indices in a manner that closely tracks variation in fit (i.e., $R^{2} \mathrm{~s}$ ) in the actual HFRI data. The Internet Appendix provides additional details regarding the simulations.

We next alter the base case to examine how model misspecification impacts the correlation in estimated filtered returns when true filtered returns are independent. We begin with the case of a missing factor. We assume the underlying return generating process is a 2-factor model, where the second (independent) factor is unobserved; as a result, some of the observed residual variance arises from the missing factor. For tractability, we assume the second factor has the same distributional shape as the first factor but plays a much smaller role in explaining variation in returns. Specifically, we assume the true return generating function is

$$
r_{i t}^{*}=\gamma_{i 1} F_{1 t}+k \gamma_{i 1} F_{2 t}+e_{i t}^{*},
$$

where asterisks denote new variables relative to the base case model and $k$ is a constant that ranges from 0 to 0.5 by increments of 0.01 . In all of our cases of model misspecification, we adopt a positive scaling constant $k$ such that the misspecification is 0 when $k=0$, and the base case model again obtains. Note that, here, $e_{i t}^{*}$ is a scaled value of $e_{i t}$ such that changing $k$ (the "importance" of the missing factor) does not change the total variance of returns (i.e., $\left.\sigma^{2}\left(r_{i t}^{*}\right)=\sigma^{2}\left(r_{i t}\right)\right)$. This framework allows for a simple interpretation of the relative importance of the second factor as $F_{2 t}$ accounts for $\left(k^{2} /\left(1+k^{2}\right)\right) \%$ of systematic return variance. For instance, if $k=0.25, F_{1 t}$ explains $94 \%$ of the variation systematic returns while $F_{2 t}$ explains the remaining $6 \%$.

Assuming we can only observe the first factor $\left(F_{1 t}\right)$, we estimate filtered returns from the misspecified model for each of the 1,000 samples for $k=0$ to 0.5 by increments of 0.01 . Thus, the estimated filtered returns are

$$
v_{i t}=r_{i t}^{*}-a_{i 0}-a_{i 1} F_{1 t},
$$

where $a_{i 0}$ and $a_{i 1}$ are the ordinary least squares (OLS) regression coefficients from a regression of equation (2) returns $\left(r_{i t}^{*}\right)$ on the first factor $\left(F_{1 t}\right)$. The "missing factor" curve in Figure 5 presents the mean correlation in estimated filtered returns $\left(v_{i t}\right)$ across the 1,000 simulated residual series for all 28 possible pairs (i.e., $n(n-1) / 2, n=8$ indices) of hedge funds (when true filtered returns, $e_{i t}^{*}$, are independent) and for various levels of second factor importance, as determined by $k$ (the horizontal axis). The horizontal line is the mean filtered return correlation in the actual HFRI data from Panel B of Table 1.

The results reveal that the lines cross at $k=0.39$, implying that, even if the model was perfectly specified in every other way (i.e., factors are measured without any error, betas are constant and perfectly estimated, and reported returns fully reflect actual returns for the same period), a single missing factor that accounts for $13 \%$ of the variance in systematic returns (i.e., $0.39^{2} /\left(1+0.39^{2}\right)=0.13$ ) would 


\section{FIGURE 5}

\section{Simulations: Model Misspecification and Return Dependence}

Figure 5 reports the mean correlation in estimated filtered returns as a function of the extent of misspecification $(k)$ for four possible sources of misspecification. True filtered returns are always independent, and in all cases, there is no misspecification when $k=0$. The horizontal line is the average correlation observed in the data (from Panel B of Table 1). The four possible cases of misspecification include the following: i) when a factor that explains $k^{2} /\left(1+k^{2}\right) \%$ of the systematic return variance is missing from the estimated model, ii) when a single factor drives systematic return but that factor is measured with error that accounts for $k^{2} /\left(1+k^{2}\right) \%$ of the variance in the observed factor realization, iii) when a single factor drives systematic returns and betas are time varying and time variation in factor loadings accounts for $k^{2} /\left(1+k^{2}\right) \%$ of the systematic return variance, and iv) when returns are smoothed such that the observed return is a function of the current and two previous returns $r_{i t}^{*}=(1-k) r_{i t}+(2 / 3) k r_{i t-1}+(1 / 3) k r_{i t-2}$.

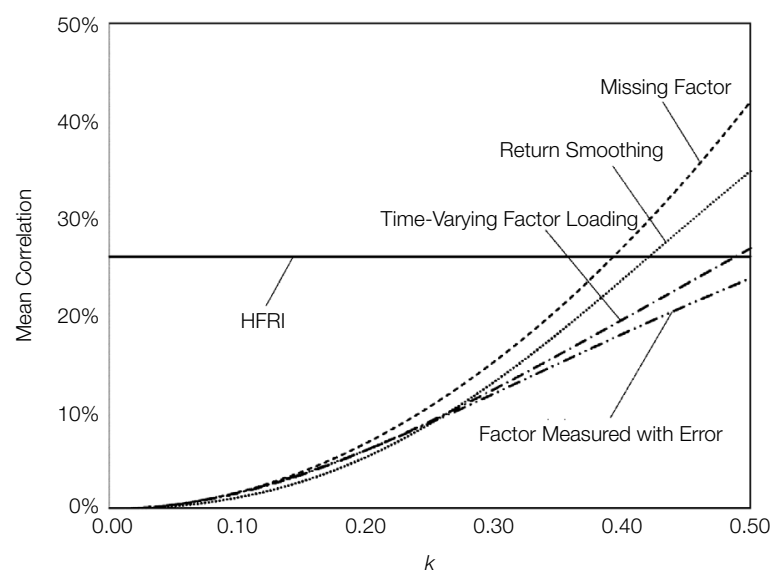

generate correlations in estimated filtered returns $\left(v_{i t}\right)$ that are equal to those observed in the data even when true filtered returns $\left(e_{i t}^{*}\right)$ are independent.

Our second simulation examines how factor mismeasurement influences dependence in estimated filtered returns. Specifically, we modify the base case by assuming the single systematic factor $\left(F_{1 t}\right)$ is measured with error:

$$
F_{1 t}^{*}=F_{1 t}+k e_{F t},
$$

where $k$ is again a constant and $e_{F t}$ is a standard normal random shock. Although equation (1) is the true model, we assume that we can only observe the factor measured with error $\left(F_{1 t}^{*}\right)$ and, therefore, estimate

$$
v_{i t}=r_{i t}-a_{i 0}-a_{i 1} F_{1 t}^{*},
$$

where $a_{i 0}$ and $a_{i 1}$ are the OLS regression coefficients from regressing the returns from equation (1) on the factor measured with error $\left(F_{1 t}^{*}\right)$. This framework implies (see the Internet Appendix for proof) that the fraction of observable factor variance attributed to noise is given by $\left(k^{2} /\left(1+k^{2}\right)\right)$.

As before, we increase $k$ by increments of 0.01 from $k=0$ to 0.50 and estimate 1,000 simulations (of 228 months) for each of the eight indices. The "factor measured with error" curve in Figure 5 reports the mean correlations in estimated filtered returns when true filtered returns are independent but the systematic factor is measured with error. The results reveal that, if the only misspecification was that true systematic factor realization accounts for $80 \%$ of the variation in the 
observed systematic factor (i.e., at $\left.k=0.5, k^{2} /\left(1+k^{2}\right)=0.20\right)$, noise in the factor realization alone could explain nearly all the correlation observed in the HFRI filtered returns (i.e., the average correlation in Panel B of Table 1).

Our third simulation examines how time-varying factor loadings influence dependence in estimated filtered returns when true filtered returns are independent. Specifically, we assume there is a common component to time-varying factor loadings. Thus, the return generating process becomes

$$
r_{i t}^{*}=\gamma_{i 1 t}^{*} F_{1 t}+e_{i t}=\gamma_{i 1} F_{1 t}+k e_{\gamma t} \gamma_{i 1} F_{1 t}+e_{i t},
$$

where $e_{\gamma t}$ is a standard normal random shock (common to all indices) and $k$ is constant. This framework implies that the time-varying factor loadings account for $\left(k^{2} /\left(1+k^{2}\right)\right) \%$ of the systematic return variance (see the Internet Appendix for proof).

We then estimate filtered returns for each index with a constant factor loading,

$$
v_{i t}=r_{i t}^{*}-a_{i 0}-a_{i 1} F_{1 t},
$$

and examine the dependence across simulated series. The "time-varying factor loading" curve in Figure 5 presents the observed mean correlation in estimated filtered returns $\left(v_{i t}\right)$ across the 1,000 simulated residual series for all 28 possible pairs of hedge funds and for various levels of time variation in factor coefficients when true filtered returns $\left(e_{i t}\right)$ are independent. The results reveal that, if timevarying factor loadings explain $19 \%$ (i.e., $0.48^{2} /\left(1+0.48^{2}\right)$ ) of variation in systematic returns and the model is otherwise perfectly specified, time-varying factor loadings, by themselves, could explain the levels of filtered return correlation observed in the HFRI data.

Last, we consider return smoothing by assuming observed returns are a function of both the contemporaneous monthly (base case) return and returns over the 2 previous months:

$$
r_{i t}^{*}=(1-k) r_{i t}+\left(\frac{2}{3}\right) k r_{i t-1}+\left(\frac{1}{3}\right) k r_{i t-2},
$$

where $k$ again ranges from 0 to 0.5 by increments of 0.01 . The general form here is a simplified decay structure, where the two-period lag weight is half of the one-period weight for a given choice of $k$.

We then assume that we observe the smoothed return $\left(r_{i t}^{*}\right)$ rather than the true return $\left(r_{i t}\right)$ and compute estimated filtered returns (from the misspecified model) as

$$
v_{i t}=r_{i t}^{*}-a_{i 0}-a_{i 1} F_{1 t} .
$$

The "return smoothing" curve in Figure 5 presents the mean correlation in estimated filtered returns $\left(v_{i t}\right)$ (when true filtered returns, $e_{i t}$, are independent) across the 1,000 simulated residual series for all 28 possible pairs of hedge funds and for various levels of return smoothing. The results reveal that, at $k=0.42$ (i.e., $42 \%$ of the observed return arises from previous returns), the average correlation in estimated filtered returns is 0.26 (matching the correlation levels observed in 
Panel B of Table 1) even if the model is otherwise perfectly specified and true filtered returns are independent.

In sum, using simulated data that closely match the HFRI data, the results in Figure 5 suggest that reasonable levels in any one of the four misspecifications we consider will generate correlations of the magnitude we observe in the data.

\section{Discussion and Robustness Tests}

One potential explanation for symmetric dependence in filtered hedge fund returns is that liquidity spirals drive left tail dependence but something else drives right tail dependence. This explanation, however, requires that whatever is responsible for right tail dependence is not also symmetrically responsible for left tail dependence. ${ }^{21}$ That is, this suggestion fails to recognize that, in contrast to liquidity spirals, other asset pricing risk factors are predicted to cause symmetric commonality in both low and high returns. It is also possible that hedge funds, as a group, are harmed by negative liquidity shocks and symmetrically benefit from positive liquidity shocks. Such a pattern, however, is inconsistent with the Brunnermeier and Pedersen (2009) liquidity spiral model, where hedge fund margin and loss spirals are the underlying causes of liquidity spirals.

In addition, the Internet Appendix provides detailed results from several robustness tests. First, a possible explanation for the lack of asymmetry in Figure 1 is that liquidity shocks are sudden (Brunnermeier and Pedersen (2009), propositions (4), (5), and (6)) and the monthly data are too coarse to capture liquidity shock induced contagion. Thus, we repeat our primary tests with daily filtered returns for hedge fund indices. These tests continue to support the model misspecification explanation.

Another potential concern is that the literature's focus on filtered index returns (rather than individual fund returns) may somehow obscure contagion. It is important to recognize, however, that the Brunnermeier and Pedersen (2009) model predicts that liquidity spirals occur in all assets held by speculators (i.e., that is the source of the contagion in their model) and model misspecification is likely to be a greater issue at the fund level than the index level. Nonetheless, we run several tests based on returns for individual funds (rather than indices). We continue to find uniform support for the model misspecification explanation (see the Internet Appendix for detailed results).

While our tests are based on the Boyson et al. (2010) 14-factor model, much of the hedge fund literature focuses on the Fung and Hsieh (2004) 7-factor model. One limitation of the 7-factor model relative to the 14-factor model is that the latter includes lag returns as a regressor (to help control for return smoothing). In addition, it is possible that the liquidity contagion channel variables are themselves omitted factors. Thus, in a series of robustness tests, we repeat our analysis with three additional models: i) the 7-factor model, ii) an 8-factor model comprised of the 7-factor model and lag returns as an additional control variable (to help account for return smoothing), and iii) a 9-factor model comprised of the

\footnotetext{
${ }^{21}$ For instance, if one believes that liquidity shocks drive left tail dependence but momentum drives right tail dependence, then, implicitly, one is arguing that momentum does not impact left tail dependence as the left tail would then exhibit greater clustering than the right tail.
} 
7-factor model, lag returns, and each of the liquidity channel variables (considered one at a time). Our results (untabulated to conserve space) remain qualitatively identical. For instance, the average correlation in filtered returns is $26 \%$ using the 14-factor model (Panel B of Table 1) versus 28\% for the 7-factor model, $27 \%$ for the 8 -factor model, and $27 \%$ for the average 9 -factor model. ${ }^{22}$ Moreover, we can never reject the null of symmetry in the comovement graph with any of the models we consider. We focus on the 14-factor model because it is the most conservative (e.g., we know a missing factor will generate filtered return dependence); it includes lag returns as one of the factors, which at least partially accounts for return smoothing; and it allows direct comparison with previous work.

\section{Conclusions}

Understanding what drives the patterns in filtered hedge fund return dependence is important for understanding how markets function, the role of hedge funds in markets, and ultimately in shaping appropriate regulatory policy. The fact that at least some hedge funds appear to provide liquidity in some securities (e.g., Aragon and Strahan (2012)) leads to the possibility that liquidity shocks propagate across both securities and markets as a result of liquidity spiral induced hedge fund contagion, as modeled by Brunnermeier and Pedersen (2009). Consistent with the liquidity spiral model, extant work demonstrates that hedge fund filtered returns cluster in the left tail and the likelihood of observing left tail clustering is positively related to negative liquidity shocks.

In this study, we consider whether a competing model misspecification hypothesis can explain both filtered index return dependence and why the dependence is positively related to negative liquidity shocks. Our analysis reveals that, inconsistent with the hypothesis that liquidity spirals play a meaningful role in explaining filtered hedge fund return dependence, the clustering is symmetric. Further, consistent with the model misspecification hypothesis (and inconsistent with the liquidity spiral explanation), filtered returns for Short Bias hedge funds exhibit negative symmetric dependence relative to the filtered returns of other hedge fund indices.

Our tests also provide support for the explanation that model misspecification underlies the relation between negative liquidity shocks and hedge fund filtered return clustering. Specifically, negative liquidity shocks are more likely when fundamental volatility is high and negative liquidity shocks are associated with a greater, rather than lower, likelihood of observing clustering in the right tail. Moreover, market volatility subsumes the relation between negative liquidity shocks and hedge fund filtered return clustering in both the left and right tails. Providing further support for the hypothesis that model misspecification drives the dependence in hedge fund filtered returns and the relation between the dependence

\footnotetext{
${ }^{22}$ We estimate eight 9-factor models (one for each of the eight liquidity channel variables). However, as discussed in the paper (and the Internet Appendix), the Repo data are only available for 135 months. Because it is based on only a subset of the returns, for conservatism, we exclude the model that uses Repo data as an explanatory variable when computing the average filtered return correlation for the 9-factor model. Including the model that uses Repo data, the average correlation increases to $29 \%$ across the eight 9 -factor models.
} 
and negative liquidity shocks, we find that these patterns are also present, and of similar magnitude, in equity size ranked portfolios. Moreover, simulations reveal that relatively conservative levels of model misspecification generate substantial dependence in estimated filtered returns when true filtered returns are independent. In sum, the evidence provides uniform support for the hypothesis that model misspecification, rather than hedge fund liquidity shock induced contagion, explains both the dependence in filtered hedge fund returns and why the clustering in filtered returns is associated with negative liquidity shocks.

\section{References}

Amihud, Y. "Illiquidity and Stock Returns: Cross-Section and Time Series Effects." Journal of Financial Markets, 5 (2002), 31-56.

Aragon, G. O., and P. E. Strahan. "Hedge Funds as Liquidity Providers: Evidence from the Lehman Bankruptcy." Journal of Financial Economics, 103 (2012), 570-587.

Bekaert, G.; C. R. Harvey; and A. Ng. "Market Integration and Contagion." Journal of Business, 78 (2005), 39-69.

Ben-David, I.; F. Franzoni; and R. Moussawi. "Hedge Fund Stock Trading in the Financial Crisis of 2007-2008." Review of Financial Studies, 25 (2012), 1-54.

Bollen, N. "Zero $R^{2}$ Hedge Funds and Market Neutrality." Journal of Financial and Quantitative Analysis, 48 (2013), 519-547.

Bollen, N., and R. Whaley. "Hedge Fund Risk Dynamics: Implications for Performance Appraisal." Journal of Finance, 64 (2009), 985-1035.

Boyson, N. M., and C. W. Stahel. "Liquidity and Hedge Fund Contagion." In Financial Contagion: The Viral Threat to the Wealth of Nations, R.W. Kolb, ed. Hoboken, NJ: John Wiley \& Sons, Inc. (2010).

Boyson, N. M.; C. W. Stahel; and R. M. Stulz. "Hedge Fund Contagion and Liquidity Shocks." Journal of Finance, 65 (2010), 1789-1816.

Boyson, N. M.; C. W. Stahel; and R. M. Stulz. "Liquidity Shocks and Hedge Fund Contagion.” Journal of Investment Management, 10 (2012), 13-34.

Brown, S. J.; G. N. Gregoriou; and R. Pascalau. "Diversification in Funds of Hedge Funds: Is It Possible to Overdiversify?" Review of Asset Pricing Studies, 2 (2012), 89-110.

Brunnermeier, M. K., and S. Nagel. "Hedge Funds and the Technology Bubble." Journal of Finance, 54 (2004), 2013-2040.

Brunnermeier, M. K., and L. H. Pedersen. "Market Liquidity and Funding Liquidity." Review of Financial Studies, 22 (2009), 2201-2238.

Cao, C.; Y. Chen; W. N. Goetzmann; and B. Liang. "The Role of Hedge Funds in the Security Price Formation Process.” Working Paper, Penn State University, Texas A\&M University, Yale University, University of Massachusetts at Amherst (2016).

Cao, C.; B. Liang; A. W. Lo; and L. Petrasek. "Hedge Fund Holdings and Stock Market Efficiency." Review of Asset Pricing Studies, forthcoming (2017).

Cappiello, L.; B. Gérard; A. Kadareja; and S. Manganelli. "Measuring Comovements by Regression Quantiles.” Journal of Financial Econometrics, 12 (2014), 645-678.

Cappiello, L.; A. Kadareja; and S. Manganelli. "The Impact of the Euro on Equity Markets." Journal of Financial and Quantitative Analysis, 45 (2010), 473-502.

Chakrabarty, B., and G. Zhang. "Credit Contagion Channels: Market Microstructure Evidence from Lehman Brothers’ Bankruptcy.” Financial Management, 41 (2012), 320-343.

Dudley, E., and M. Nimalendran. "Margins and Hedge Fund Contagion." Journal of Financial and Quantitative Analysis, 46 (2011), 1227-1257.

Engle, R. F.; E. Ghysels; and B. Sohn. "Stock Market Volatility and Macroeconomic Fundamentals." Review of Economics and Statistics, 95 (2013), 776-797.

Fleishman, A. "A Method for Simulating Non-Normal Distributions." Psychometrika, 43 (1978), $521-532$.

Fung, W., and D. A. Hsieh. "The Risk in Hedge Fund Strategies: Theory and Evidence from Trend Followers." Review of Financial Studies, 14 (2001), 313-341.

Fung, W., and D. A. Hsieh. "Benchmarks of Hedge Fund Performance: Information Content and Measurement Biases.” Financial Analysts Journal, 58 (2002), 22-34.

Fung, W., and D. A. Hsieh. "Hedge Fund Benchmarks: A Risk-Based Approach." Financial Analysts Journal, 60 (2004), 65-80. 
Fung, W., and D. A. Hsieh. "Measurement Biases in Hedge Fund Performance Data: An Update." Financial Analysts Journal, 65 (2009), 1-3.

Hanson, S., and A. Sunderam. "The Growth and Limits of Arbitrage: Evidence from Short Interest." Review of Financial Studies, 27 (2014), 1238-1286.

Nagel, S. "Evaporating Liquidity." Review of Financial Studies, 25 (2012), 2005-2039.

Nagelkerke, N. J. D. “A Note on a General Definition of the Coefficient of Determination.” Biometrika, 78 (1991), 691-692.

Norris, F. "Improving the Ability to Foretell Crisis: High and Low Finance." International Herald Tribune (Jan. 11, 2013).

Pastor, L., and R. Stambaugh. "Liquidity Risk and Expected Stock Returns.” Journal of Political Economy, 111 (2003), 642-685.

Patton, A. J. "Are 'Market Neutral' Hedge Funds Really Market Neutral?" Review of Financial Studies, 22 (2009), 2495-2530.

Patton, A. J., and T. Ramadorai. "On the High-Frequency Dynamics of Hedge Fund Risk Exposures." Journal of Finance, 68 (2013), 597-635.

Sadka, R. "Momentum and Post-Earnings-Announcement Drift Anomalies: The Role of Liquidity Risk." Journal of Financial Economics, 80 (2006), 309-349.

Schwert, G. W. "Why Does Stock Market Volatility Change over Time?" Journal of Finance, 44 (1989), 1207-1239.

Sialm, C.; Z. Sun; and L. Zheng. "Home Bias and Local Contagion: Evidence from Funds of Hedge Funds." Working Paper, University of Texas at Austin and University of California, Irvine (2014).

Sias, R.; H. J. Turtle; and B. Zykaj. "Hedge Fund Crowds and Mispricing." Management Science, 62 (2016), 764-784.

Stein, J. C. "Presidential Address: Sophisticated Investors and Market Efficiency." Journal of Finance, 64 (2009), 1517-1548.

Teo, M. "The Liquidity Risk of Liquid Hedge Funds." Journal of Financial Economics, 100 (2011), 24-44.

Titman, S., and C. Tiu. "Do the Best Hedge Funds Hedge?" Review of Financial Studies, 24 (2011), $123-168$. 